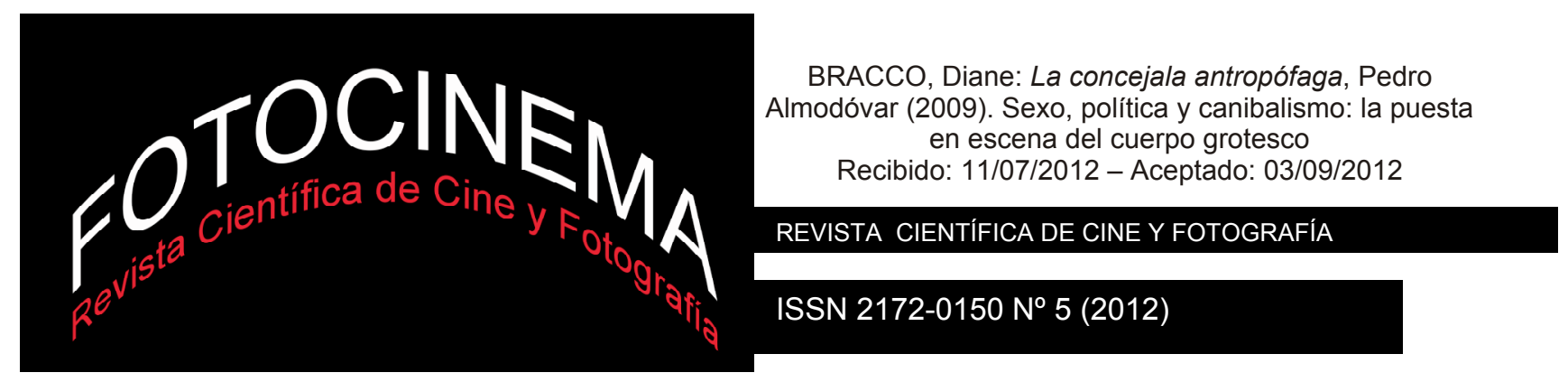

\title{
LA CONCEJALA ANTROPÓFAGA, PEDRO ALMODÓVAR (2009). SEXO, POLÍTICA Y CANIBALISMO: LA PUESTA EN ESCENA DEL CUERPO GROTESCO
}

\section{LA CONCEJALA ANTROPÓFAGA, PEDRO ALMODÓVAR (2009). SEX, POLITICS AND CANNIBALISM: THE STAGING OF THE GROTESQUE BODY}

\section{Diane Bracco}

Universidad de París 8

\section{Resumen:}

En 2009, durante el rodaje de Los abrazos rotos, Pedro Almodóvar dirige un cortometraje cómico, La concejala antropófaga, pretexto para un juego de reescritura paródica y emblemático de las conexiones transtextuales que se establecen en toda la producción almodovariana. Este artículo se propone esbozar un análisis del relato fílmico desde la perspectiva grotesca bajtiniana. Se tratará de determinar en qué medida sexo, política y canibalismo se conjugan para forjar una figura grotesca propicia a una celebración de la materialidad del cuerpo, celebración teñida de sátira política. El personaje de la concejala golosa, cocainómana y ninfómana se caracteriza por una tendencia al desbordamiento -físico y verbal- y un exceso de vitalidad sintomáticos de la relación dialógica que ella mantiene con el mundo. Figura humana con vigor sobrehumano, aparece como un ser híbrido y monstruoso, un organismo excéntrico en el sentido grotesco del término, ansioso de devorar literalmente el mundo. Tal exaltación del cuerpo grotesco se plasma en un monólogo a medio camino entre la confesión íntima y el discurso político, verdadera sátira de la retórica derechista.

\begin{abstract}
:
In 2009, during the shooting of $L o s$ abrazos rotos, Pedro Almodóvar directed a comic short film, L a concejala antropófaga, in which he indulged in a game of parodical rewriting, emblematic of the transtextual connections that are woven into his entire work. Through this article, we wish to lay the basis for an analysis of the film narrative from the perspective of Bakhtin's "grotesque". We will determine how sex, politics and cannibalism combine to forge a grotesque figure conducive to a celebration of the materiality of the body-a celebration tinged with political satire. The greedy town councillor, a cocaine addict as well as a nymphomaniac, is characterised by her tendency to overflow - both physically and verbally- and by her excess of vitality, which are the symptoms of the dialogic relationship she establishes with the world. This human figure endowed with a superhuman vigour seems to be a hybrid, monstrous being-an eccentric body in the grotesque meaning of the word, eager to literally devour the world. Such an exaltation of the grotesque body is made through a monologue which is halfway between intimate confession and political discourse, thus constituting a genuine satire of right-wing rhetoric.
\end{abstract}

\section{Palabras clave:}

Almodóvar, transtextualidad, grotesco, canibalismo, sátira.

\section{Key words:}

Almodóvar, transtextuality, grotesque, cannibalism, satire. 
En 2009, durante el rodaje de Los abrazos rotos, Pedro Almodóvar dirige La concejala antropófaga: este cortometraje de 7’31 se emite en Internet a modo de teaser a fin de promover el estreno de la película protagonizada por Lluis Homar y Penélope Cruz. El espectador de Los abrazos rotos identifica a posteriori la única secuencia que constituye este breve relato fílmico como un fragmento de Chicas y maletas, la obra realizada por el personaje de Mateo Blanco (Lluis Homar) en la diégesis del largometraje. La concejala antropófaga hace eco a otro pasaje de este filme ficticio inserto según un procedimiento de mise en abyme en la penúltima obra de Almodóvar: dicho pasaje se inscribe en el relato de primer nivel de Los abrazos rotos, que narra los desengaños de Mateo para llevar a cabo su proyecto. El montaje de la película es saboteado a petición del productor Ernesto Martel (José Luis Gómez), celoso de la relación clandestina que su mujer Lena (Penélope Cruz), la actriz que encarna Pina -protagonista de Chicas y maletas-, mantiene con Mateo. Esta estructura narrativa de cajas chinas así como el tema de la dirección generan una reflexión no sólo en torno al acto cinematográfico y al proceso de creación sino también acerca de las redes intertextuales en la producción almodovariana. En efecto, el cortometraje se inserta en un entramado de guiños y es pretexto para un juego de reescritura: una conexión se establece primero con la obra que pretende promover, en particular el fragmento de relato fílmico integrado en Los abrazos rotos. Dicho fragmento plantea el decorado e introduce al personaje de la concejala interpretado por Carmen Machi ${ }^{1}$, desarrollado en la secuencia que constituye La concejala antropógafa. Además, el filme metadiegético Chicas y maletas, al que pertenecen estos dos pasajes contiguos en su desarrollo dramático, resulta ser un hipertexto de Mujeres al borde de un ataque de nervios (1989). Gérard Genette define esta forma transtextual del modo siguiente:

\footnotetext{
${ }^{1}$ Apareció antes en Hable con ella (2002), donde interpretaba una enfermera, colega de uno de los protagonistas masculinos, Benigno. Su papel muy breve ya la vinculaba con la temática de la corporalidad: en el ejercicio de sus funciones, el personaje tenía que cuidar de pacientes en coma, organismos inertes reducidos a sus funciones vitales mínimas.
} 
J'entends par là toute relation unissant un texte B (que j'appellerai hypertexte) à un texte antérieur A (que j'appellerai, bien sûr, hypotexte) sur lequel il se greffe d'une manière qui n'est pas celle du commentaire. ${ }^{2}$

Penélope Cruz retoma el personaje de Pepa-Carmen Maura, abandonada por su pareja. Vuelve a aparecer el tema de la ruptura amorosa (en ambos relatos, la protagonista busca desesperadamente contactar con su amante Iván, esposo infiel de una mujer psíquicamente desequilibrada), que se declina en distintos motivos: la cama quemada, la maleta y el gazpacho con somníferos que esta mujer al borde de un ataque de nervios le destina al fugitivo (la mixtura es ingerida por Marisa en Mujeres y por Maribel en el cortometraje). Si una primera maleta materializa para Pina la separación y el imposible diálogo amoroso, existe otra que Chon afirma haber encontrado por casualidad en su armario, descubriendo kilos de cocaína al abrirla. A la par que devora golosamente unas magdalenas, cuenta su relación fugaz con un desconocido, amante "virtuoso" pero también peligroso narcotraficante perseguido por la policía, que habría dejado dicha maleta en su casa. El personaje de Chon reactualiza, pues, el de la ingenua Candela en Mujeres, amiga de Pepa, desesperada tras haberse percatado de que su última conquista no era sino un terrorista chiita. Dicho de otro modo, lo que nos propone Almodóvar a través de esta secuencia de Chicas y maletas es una relectura condensada de la trama de la película de 1989.

La concejala antropófaga se sitúa a un doble nivel y realza el vínculo que une a ambos creadores, Almodóvar y Mateo Blanco, su alter ego en Los abrazos rotos. Mateo asume de paso una segunda identidad puesto que escribe guiones bajo el seudónimo de Harry Caine. Por una parte, el espectador se halla ante un cortometraje, una unidad independiente provista de una coherencia propia (con títulos de crédito, un mundo diegético y una progresión dramática) dirigido por el cineasta manchego en una perspectiva promocional. Por otra parte, se trata de una de las secuencias de una película

\footnotetext{
${ }^{2}$ GENETTE, Gérard, Palimpsestes. La littérature au second degré, Paris, Seuil, 1982, p. 13. "Entiendo por ello toda relación que une un texto B (que llamaré hipertexto) a un texto anterior A (que llamaré hipotexto) (sic) en el que se inserta de una manera que no es la del comentario." (traducción española de Celia Fernández Prieto).
} 
ficticia titulada Chicas y maletas, rodada por un director no menos ficticio, personaje diegético de Los abrazos rotos; una secuencia que, no obstante, Almodóvar no incorpora en su película. La fusión de ambos estatutos y el cruce de los mundos diegético y extradiegético se materializan en los títulos de crédito: La concejala antropófaga se presenta como una realización de Mateo Blanco, con guión de Harry "Huracán” Caine, informaciones que remiten a la doble identidad del personaje ficticio de Los abrazos rotos. Pero el cortometraje está relacionado asimismo con la filmografía almodovariana y por consiguiente con un director real ya que se señala al final que "El Guión está inspirado en un personaje anecdótico de Los Abrazos Rotos de Pedro Almodóvar”. A continuación, los títulos de crédito mencionan al equipo técnico de Los abrazos rotos y la compañía productora de Pedro Almodóvar, El Deseo. Esta doble aprensión del relato fílmico así como la descodificación de la referencia intertextual son permitidas por la complicidad lúdica que el cineasta establece con su espectador: éste queda libre de integrar a su vez la ficción como público de un cineasta imaginario, Mateo, o de visionar el último cortometraje que un director de carne y hueso, Almodóvar, dirige para promover su nueva película.

Aunque la meta-secuencia de Chicas y maletas incluida en Los abrazos rotos le ofrece a Pina (Lena-Penélope Cruz) un papel de primer plano -es indudablemente la heroína de la obra de Mateo Blanco, al igual que PepaCarmen Maura es la de Mujeres-, La concejala antropófaga la excluye desde los primeros segundos, como lo sugiere el título, para enfocarse en Chon, la interlocutora locuaz de Pina en el fragmento que precede cronológicamente esta secuencia. La figura de la concejala se sitúa en las antípodas no sólo de la frágil Candela sino también del modelo hollywoodiense a partir del que la actriz plasma el personaje de Pina: Audrey Hepburn, cuyos peinado, atuendo y expresión maliciosa imita3. Además, sus extravagantes consideraciones políticas y sexuales tienen poco que ver con el amour fou trágico que une a Mateo, Lena y Ernesto: paradójicamente, La concejala antropófaga se

3 El homenaje al cine americano aparece claramente en la secuencia de la sesión de fotos de Los abrazos rotos: Lena prueba varias pelucas, reproduce las mímicas de las actrices hollywoodienses y se transforma por unos instantes en Marilyn Monroe o Audrey Hepburn. 97 
presenta como el teaser cómico del drama que pone en escena la pasión de estos tres seres. Almodóvar bosqueja el retrato de un personaje excesivo, risible, que se define en el título del cortometraje por unas prácticas antropófagas anunciadoras de su sentido de la desmesura y del desbordamiento. Este trabajo propone esbozar una reflexión sobre el cortometraje, que no parece haber sido objeto de análisis fílmicos hasta ahora. Se procurará determinar en qué medida sexo, política y canibalismo se conjugan para forjar una figura grotesca propicia a una celebración de la materialidad del cuerpo, celebración teñida de sátira política.

\section{Chon, figura del exceso}

A diferencia de la joven Pina, morena y vestida de blanco y negro, Chon, corpulenta cuarentona, exhibe una feminidad llamativa que se expresa visualmente a través de toda una gama de colores cálidos [fotos 1 y 2], desde su corta cabellera roja hasta su vestido color naranja chillón pasando por su
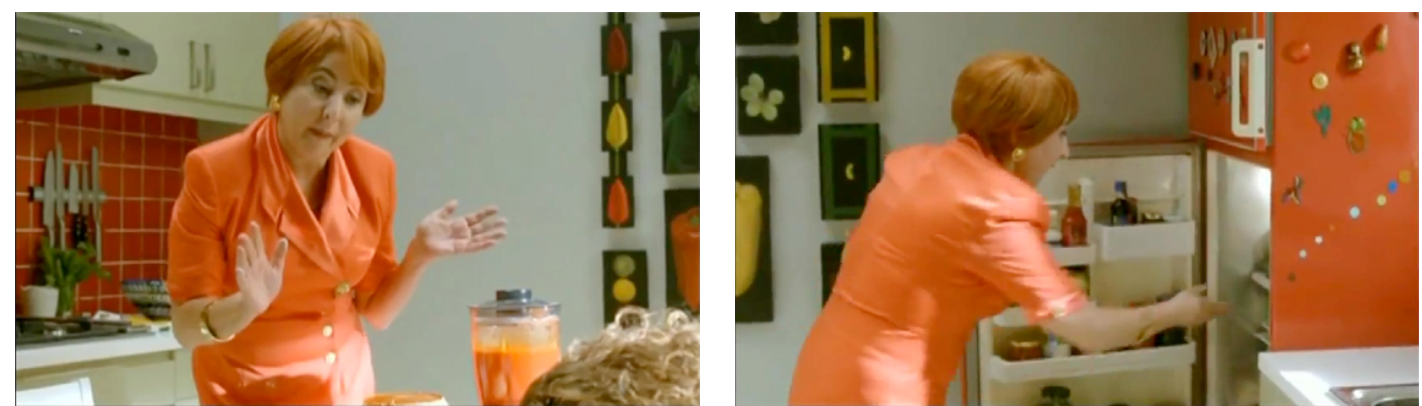

bolso de charol, sus joyas y botones dorados y sus uñas carmín. Otros toques rojos y naranjados completan este juego cromático en el espacio de la cocina donde se desarrolla la totalidad del cortometraje: la batidora que contiene un líquido naranja (la secuencia inserta en el relato de primer grado de Los

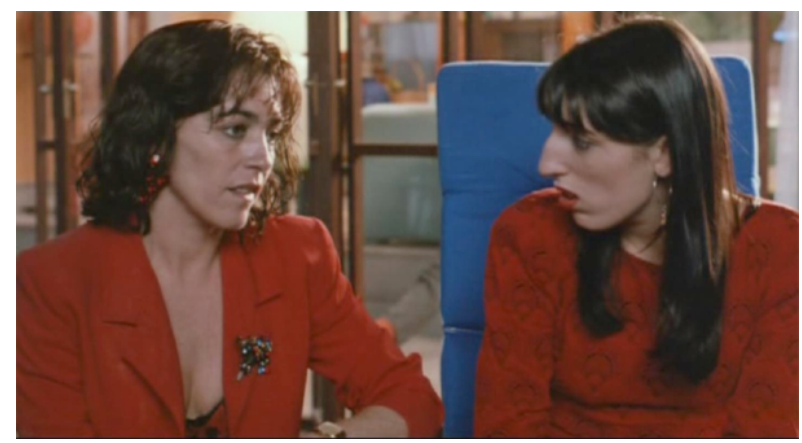
abrazos rotos y el desciframiento de la referencia a Mujeres permiten identificar la naturaleza de esta preparación: es un gazpacho con Morfidales), los azulejos 
bermellón en el trasfondo, la nevera color naranja, los cuadros en la pared que representan pimientos, la bandeja adornada con reproducciones coloridas de botellas de Coca Cola a la manera de Andy Warhol. El predominio de estos tonos recuerda los colores saturados que caracterizan el universo de Mujeres al borde de un ataque de nervios -sobre todo los atuendos femeninos [foto 3] y el piso de Pepa- y la conexión de la obra almodovariana con la estética pop, influencia particularmente sensible en las primeras películas del director (Pepi, Luci, Bom y otras chicas del montón, Laberinto de pasiones, Entre tinieblas). El plano que sigue al prólogo, tras la partida de Pina, y el que cierra el cortometraje aparecen asimismo como reminiscencias del cromatismo pop: en ambos casos, la imagen - un plano americano o medio corto de Chon - se inmoviliza y se tiñe de colores primarios, amarillo y / o azul. El primer plano inicial de la protagonista en el
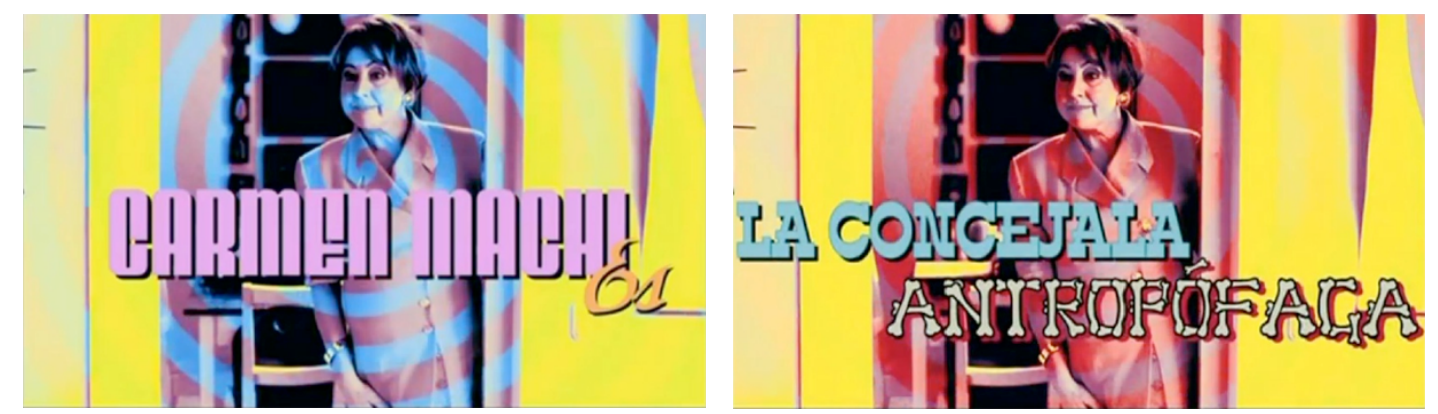

umbral de la cocina inaugura los títulos de crédito: el nombre de Carmen Machi aparece en letras mayúsculas moradas y una espiral roja movediza se superpone a la imagen fija [foto 4]. Las dos partes del título aparecen a ambos lados del campo: LA CONCEJALA en letras capitales azules, ANTROPÓFAGA en una grafía que remite visualmente al tema de la antropofagia [foto 5]. De igual modo, al final, los títulos de crédito desfilan por un plano medio corto de Chon teñido de azul y se asiste a un lento cierre en

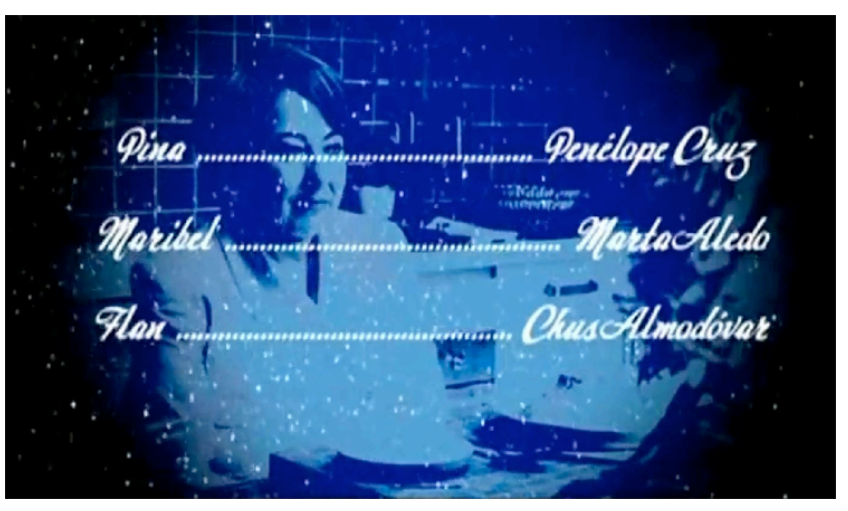
iris [foto 6]. 
Todos estos procedimientos convocan entre otras cosas en la mente del espectador el recuerdo del universo coloreado del primer largometraje de Almodóvar, Pepi, Luci, Bom y otras chicas del montón, crónica de la Movida en la encrucijada de las estéticas pop, cómic y punk, (Vidal, 2000: 15-38), el de su "comedia disparatada" Laberinto de pasiones (Vidal, 2000: 39-65) o las visiones místicas de Sor Estiércol, monja drogadicta en Entre tinieblas (Vidal, 2000: 66-107) [foto 7]. Más allá del simple guiño intertextual y del "autohomenaje", La concejala antropófaga pone de relieve el designio autófago de un cineasta que parece haber ingerido y digerido sus propias obras para dar a luz un filme en el que recicla algunas de sus primeras influencias.

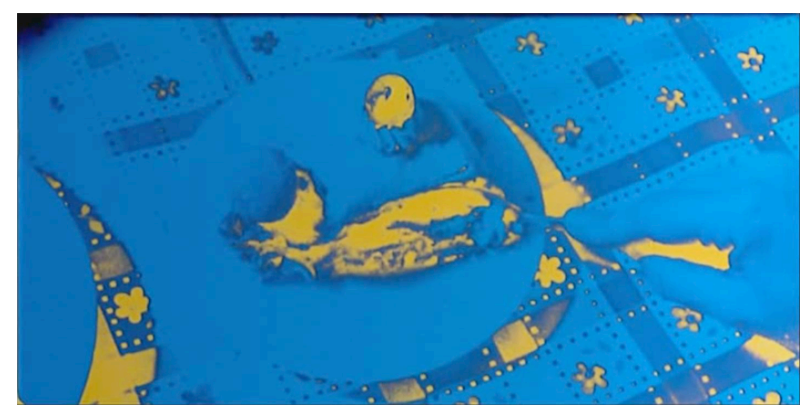

El director ha hecho de la desmesura un axioma de su obra: el exceso caracteriza la puesta en escena de las aventuras de numerosas figuras almodovarianas, personajes intensos y extremos. Que éstos protagonicen comedias extravagantes o que intervengan de modo anecdótico en realizaciones más oscuras (piénsese en la prostituta Cristal en ¿Qué he hecho yo para merecer esto?, comedia de acento neorrealista), se mueven generalmente por espacios urbanos en plena efervescencia y persiguen una búsqueda: de un pasado, de una identidad o del objeto de su deseo. Chon se inserta de lleno en esta genealogía. Su energía desbordante es sintomática de un deseo al que procura satisfacer a toda costa, así como de una fuerza dionisíaca que se traduce por una insaciable ansia vital y una voluntad de devorar literalmente el mundo. En este sentido, encarna el espíritu grotesco tal como lo define Mijaíl Bajtín en su estudio de la cultura popular en la Edad Media y el Renacimiento: el cuerpo grotesco es un organismo en movimiento perpetuo que se crea, se construye y se regenera mediante una constante interpenetración con el mundo (Bakhtine, 1965: 302-305). Aunque los vaivenes de Chon permanecen confinados en el 
espacio reducido de la cocina, ella aparece como un personaje agitado, que se mueve continuamente de la mesa de la cocina al frigorífico, del frigorífico a la encimera, de la encimera a la silla en la que vuelve a sentarse antes de levantarse de nuevo. La cámara efectúa discretos movimientos para encuadrar mejor o seguir al personaje y la impresión de cinetismo que emana de los escasos planos que componen el cortometraje procede en realidad esencialmente de los desplazamientos de la protagonista. Su agitación y sus desbordamientos de energía se ven además subrayados por el inmovilismo total de la mujer dormida en la mesa de la cocina, espectadora pasiva e inconsciente de una prestación que se puede calificar de teatral. La exageración llevada hasta sus últimos extremos y la hipérbole que raya en la monstruosidad, dos elementos definitorios de la estética grotesca según $\mathrm{H}$. Schneegans (Bakhtine, 1965: 304-305), citado por Bajtín, se manifiestan en este personaje caracterizado por su propensión a rebasar los límites de su propia humanidad. Su inagotable vitalidad y su glotonería desaforada hacen de ella un ser surreal y monstruoso: híbrida con apariencia humana y vigor sobrehumano, Chon se sitúa al margen de la norma que define al común de los mortales. Esta relación entre centro y periferia constituye precisamente la clave de la estética grotesca (Fauconnier-Eizyman, 2003: 17-19): excesiva y por lo tanto literalmente ex-céntrica, la figura de la concejala es eminentemente grotesca. Por cierto, recuerda a otras dos encarnaciones del exceso en la obra de Almodóvar, Sexilia, la ninfómana de Laberinto de pasiones, y Patty Diphusa, heroína multiorgásmica de los escritos publicados por el cineasta en la revista La Luna a principios de los años 19804. El organismo de Chon resulta ser la sede de fantasías antropófagas y el lugar de la circulación del deseo, palabra clave en el universo almodovariano. El deseo parece ser el motor de sus desplazamientos y desahogos verbales, al igual que debería ser desde el punto de vista del personaje "el principal motor de una sociedad mejor”. Verdadero ímpetu vital, anima a un organismo sobrehumano que la concejala alimenta con flan y cocaína. A falta de

4 Como Chon, Patty Diphusa padece insomnio: estrella del cine pornográfico, se pasa las noches vagando incansablemente por la ciudad, en busca de nuevos amantes susceptibles de satisfacer su apetito sexual desaforado. Véase (Lenquette, 2000: 75-92) . 
encontrar el sueño, Chon regenera su energía alternando cucharadas golosas y dosis de droga sacadas de dos grandes platos que la cámara barre en primer plano [fotos 8-9].
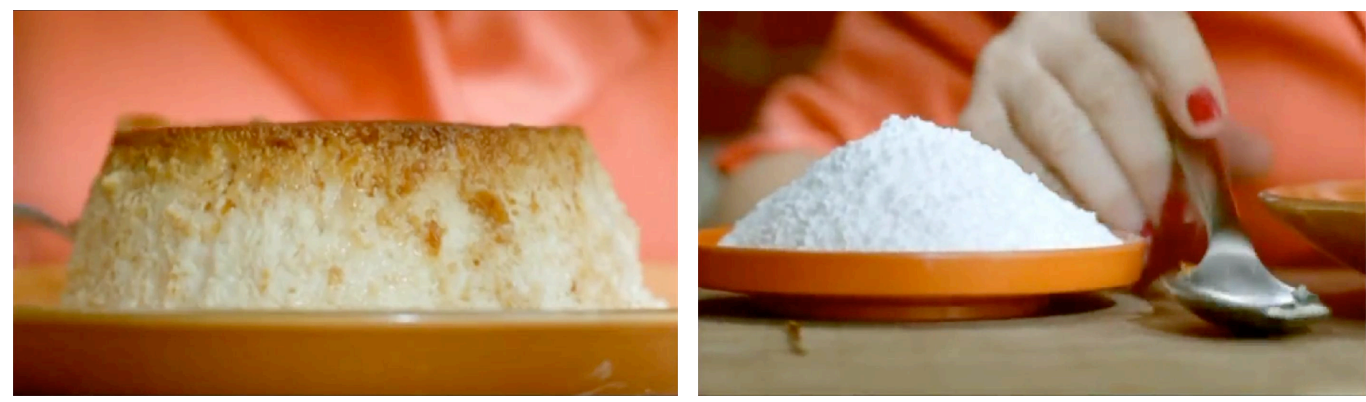

Emanación del cuerpo grotesco, la verborrea constituye otra expresión del exceso encarnado por la impetuosa concejala. La rapidez del flujo de palabras de Chon y sus modulaciones de voz se conjugan con una gestualidad exagerada y refuerzan el impacto y el alcance cómico de un monólogo a medio camino entre el discurso político y la confesión íntima. La protagonista se dirige a una interlocutora dormida, drogada con somníferos (lo cual se adivina a raíz del desciframiento del vínculo hipertextual y de la referencia al personaje de Marisa en Mujeres) y por lo tanto silenciosa: le da explicaciones como si la otra la escuchara atentamente, le hace preguntas sin esperar respuesta, poco preocupada por las razones del estado letárgico de su oyente. Machaca a la vez verbal y físicamente sus convicciones sexuales y políticas, acompañando algunas de sus aserciones de golpecitos repetidos en la mesa de la cocina ("Hay que incentivar la cultura de la promiscuidad", "Le dije que ése es el problema del PAP”). La boca se halla, pues, en el centro de la dinámica de este cuerpo grotesco ya que es de la cavidad bucal de donde brota el incontrolable torrente de palabras: es sede del Verbo pero también, como vamos a ver ahora, instrumento de la devoración.

\section{Devorar el mundo}

El término antropófaga en el título del cortometraje, del que la última réplica de Chon se hace eco ("Pues yo creo que la antropofagia te ha sentado muy bien. Estás radiante.”), tiene un valor programático pues anuncia las 
variaciones en torno al tema del canibalismo y de la devoración. La concejala confiesa desde el principio de su monólogo estar harta "de las dietas, de los colágenos, de las liposucciones”, sintomáticos de la delgadez obsesiva en una sociedad que refrena cualquier forma de gozo relacionado con la comida, y al rato saca de la nevera un enorme flan 5 del que engulle algunas cucharadas con una delectación ostensible (en la otra secuencia de Chicas y maletas, el espectador ya la veía comerse las magdalenas que Pina tenía guardadas en un armario). El hedonismo de la concejala parece corroborar las observaciones de Bajtín cuando afirma que

[l]a rencontre de l'homme avec le monde qui s'opère dans la bouche grande ouverte qui broie, déchire et mâche est un des sujets les plus anciens et les plus marquants de la pensée humaine. L'homme déguste le monde, sent le goût du monde, l'introduit dans son corps, en fait une partie de soi. ${ }^{6}$

La absorción del pastel materializa esta interacción con el mundo, que se opera vía la boca. Ésta permite "saborearlo", integrarlo y, como los otros orificios o excrecencias de la anatomía humana, saca a la luz el aspecto irregular e inacabado del cuerpo grotesco, organismo en mutación perpetua que se deja penetrar por su entorno: el mundo entra en el cuerpo, circula por dentro o sale de él, revelando fronteras porosas entre ambos espacios. Como se ha señalado antes, la degustación se acompaña de la inhalación de algunas dosis de la droga7 que Chon ha sacado previamente de su bolso y ha

5 El flan es considerado como un verdadero personaje en este cortometraje, como lo sugieren humorísticamente los títulos de crédito: aparece después de los nombres de Pina y Maribel, respectivamente encarnadas por Penélope Cruz y Marta Aledo. Fue cocinado por la hermana de Pedro Almodóvar, Chus, cuyo nombre viene a continuación del de las actrices (fotograma 6): este detalle de los títulos de crédito traduce el placer lúdico de un cineasta que no duda en integrar a sus parientes a su propio proceso de creación. Almodóvar también parece establecer de alguna forma un paralelismo entre la elaboración del flan y la realización de la película.

${ }_{6}^{6}$ Bakhtine, M., op. cit., p. 280. "el encuentro del hombre con el mundo que se opera en la boca abierta de par en par que muele, despedaza y mastica es uno de los asuntos más antiguos y más relevantes del pensamiento humano. El hombre saborea el mundo, siente el sabor del mundo, lo introduce en su cuerpo, hace de él una parte de sí mismo." (traduce la autora)

7 La temática de la droga cruza toda la obra de Almodóvar. El personaje de Chon se inscribe menos en la categoría de las víctimas que en aquélla de los consumidores sin complejos: aunque corre el riesgo de ser detenido - teme que la policía encuentre la maleta llena de cocaína en su casa -, no duda en usarla y proyecta también distribuirla entre los miembros de su partido. 
dispuesto en un plato: la absorción del mundo se efectúa a través de la nariz, a la vez orificio y protuberancia que favorece el diálogo con lo que se sitúa más allá de los límites del cuerpo humano ${ }^{8}$. La cocaína es un sicótropo que tiene por efectos notorios desinhibir al consumidor, creando en él el sentimiento de una infinita potencia, y quitarle toda sensación de saciedad y cansancio. La concejala drogadicta resulta ser precisamente un personaje sin límites físicos ni morales, un ser inagotable que ninguna sustancia parece poder hartar. Su corpulencia y el consumo de un flan entero reflejan un deseo de satisfacer su glotonería más allá de las necesidades reales de su propio cuerpo. Chon somete éste a una sobre-estimulación artificial y le confiesa que padece insomnio a su interlocutora, la cual está profundamente dormida ("Lo que pasa es que últimamente no duermo bien. A veces pienso que puede ser la coca.”). Por lo demás, derriba las barreras del pudor y del decoro para describir detalladamente sus experiencias íntimas y sus fantasías antropófagas, reveladoras de su insaciable apetito sexual. Así pues, esta ausencia de límites traduce una especie de bulimia existencial, una voluntad de borrar las fronteras entre el cuerpo y su entorno para que aquél pueda absorber mejor éste: la concejala utiliza su boca como un instrumento para “moler, despedazar y masticar” el mundo, erigiendo la devoración en postura vital.

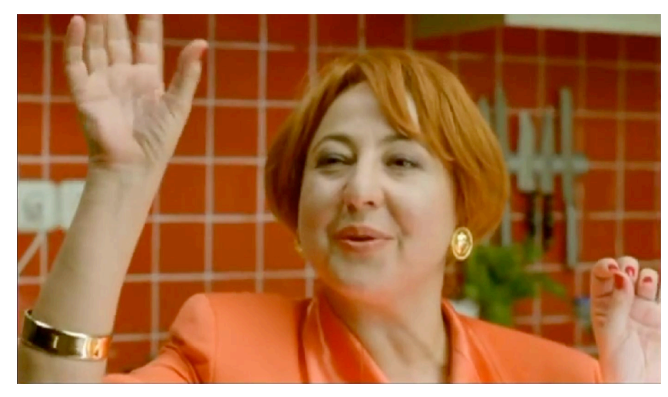

Chon relaciona explícitamente sus inclinaciones sexuales y su gusto por el buen comer en dos ocasiones: primero cuando recuerda su despertar erótico precoz e, ilustrando sus palabras con un gesto [foto 10], compara los "paquetes" masculinos con frutas que se cogen -quizás se pueda contemplar como una interpretación paródica del famoso "Carpe diem"-; luego cuando se ríe de la hipocresía de sus compañeros del ayuntamiento, arguyendo que no existe

\footnotetext{
8 Esta concepción del cuerpo grotesco se opone a los cánones literarios y plásticos clásicos, que consideran el cuerpo como una unidad rigurosamente acabada, cerrada, liberada de su materialidad, demarcada de los otros organismos y que excluye toda relación dialógica con el mundo (Bakhtine, 1965: 38-39).
} 
ninguna diferencia entre consumir pies de cerdo y comerse los pies de un hombre. En ambos casos, el elemento comparador es un alimento que remite a la idea de ingestión y connota una noción de deleite, siendo éste la finalidad del deseo que anima a la concejala. Por lo demás, la atracción de Chon por el sexo antropófago está estrechamente vinculada con la ninfomanía del personaje: la concejala confiesa estar "harta de todo [...] de todo menos del sexo", obsesión que impregna su vida profesional y sus iniciativas políticas. Defiende una visión de la sociedad resumida a una concepción del sexo como "asunto profundamente social". Esta concejala especializada precisamente en asuntos sociales reduce el buen funcionamiento de una comunidad humana a las prácticas sexuales que desde su punto de vista se deben estimular -“intercambio de parejas”, "parejas múltiples”-, en el marco del desarrollo de una cultura de la promiscuidad y de la solidaridad. En realidad, dichas prácticas no hacen sino confirmar su increíble vitalidad sexual y su inclinación por la cantidad, la sobreabundancia, la desmesura. Prosigue su monólogo evocando las fantasías que la asaltan durante las asambleas y reuniones del ayuntamiento, fantasías nutridas por su voyeurismo: "Mi único interés es mirar los culos de los tíos, sus pies, sus paquetes”. La devoración por la mirada precede, pues, la devoración por la boca y atomiza el objeto del deseo: el cuerpo masculino se ve cosificado, desmembrado, reducido a un ensamblaje de zonas erógenas. La ninfomanía de Chon se acompaña de un fetichismo por los pies, que ella usa como instrumentos de su propio placer (“Los pies... iMe vuelven loca!”). Freud define el fetichismo como una práctica que consiste en sustituir el objeto sexual normal -los genitales, que permiten el cumplimiento del acto erótico- "par un autre en rapport avec lui et qui n'est nullement approprié au but sexuel normal"9, en este caso el pie ${ }^{10}$. Éste se halla en el centro de las fantasías antropófagas de Chon: "Bueno, una de mis fantasías es comerme un tío entero empezando

\footnotetext{
9 “.... por otro en relación con él y que no es apropiado en absoluto para la meta sexual normal" (traduce la autora) (Freud, 1905: 94-95).

${ }^{10}$ Esta parte del cuerpo le permite al hombre mantenerse en pie y desplazarse pero está también cargada de connotaciones sexuales en la mitología y en la literatura: por ejemplo, el zapato de los cuentos envuelve el pie, sustituto del falo en la mujer según Freud.
}

105 
por los pies”11. El apetito sexual desaforado de Chon y su obsesión por la devoración representan una amenaza para la virilidad de los hombres que la rodean desde su más tierna infancia: recuerda con amargura que su ninfomanía precoz provocó su aislamiento, en ausencia de cualquier “pederasta” susceptible de saciar sus pulsiones. Además, supera su ruptura amorosa reciente declarándose dispuesta a consumir una nueva relación: "Mira, cuando a mí me dejó mi marido, hace unos días, le estaba cerrando la puerta y a la vez gritaba bien alto pa' que me oyera bien: 'a ver, que pase el próximo'. Salí a la calle y ahí estaba esperándome. El próximo.”12 El paso del monólogo al diálogo con Maribel, que se despierta un minuto antes del final del relato fílmico, conlleva una transferencia de la fantasía antropófaga de Chon a la joven: en efecto, ésta, que conoce a su interlocutora en esta ocasión, se abre a su vez y le cuenta haber soñado que devoraba a un hombre empezando por los pies. El inconsciente de la joven durmiente parece haber asimilado las confidencias de la concejala y las ha traducido en un sueño erótico que suscita la curiosidad de la protagonista. Este breve intercambio es pretexto para un juego por parte del director: la reescritura de la secuencia final de Mujeres al borde de un ataque de nervios [fotos 3-11]. Marisa (el juego

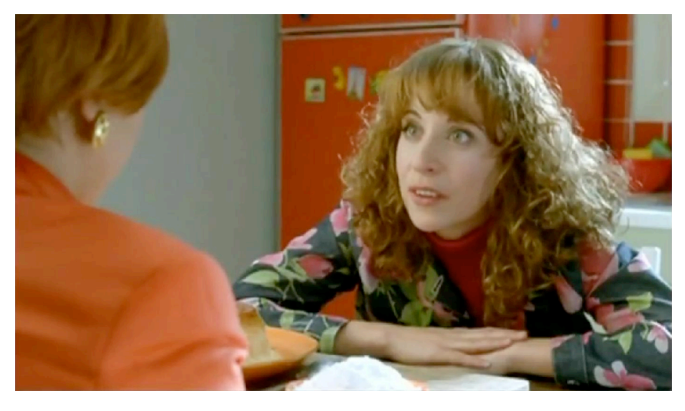
paronímico entre los nombres Marisa y Maribel subraya la conexión intertextual), drogada con los somníferos diluidos en el gazpacho, se despierta tras la resolución de conflictos a los que no ha asistido conscientemente y le confiesa a Pepa haber perdido su virginidad en sueño. En ambas películas, el gazpacho aparece entonces como una especie de elixir o de llave que permite acceder a otro mundo (Méjaen, 2004: 86-87): el del sueño y de las fantasías. El universo onírico de la joven se ha impregnado del

${ }^{11}$ La confesión de esta fantasía antropófaga recuerda la inmersión total del protagonista de Amante menguante - metarrelato fílmico inserto en el relato principal de Hable con ella en el sexo de su mujer: en ambos casos, el hombre es totalmente absorbido por el cuerpo femenino, ya por la cavidad bucal, ya por el orificio vaginal.

${ }^{12} \mathrm{El}$ "próximo" resulta ser el narcotraficante con quien Chon revela en la otra secuencia de Chicas y maletas haber mantenido una relación sexual. Al evocar el dedo gordo de su amante, se estremece de placer. 
erotismo que la concejala no ha dejado de entremezclar con sus consideraciones políticas, a lo largo de su monólogo.

\section{Discurso político y confesiones eróticas: un desfase con efecto humorístico}

El título del cortometraje pone a un mismo nivel el universo político, a través de la alusión a la función municipal de concejala, y el canibalismo erótico sugerido por el término antropófaga, comentado antes. Desde un punto de vista formal, las confesiones de Chon se insertan en un monólogo que evoca el discurso político, monólogo al que Almodóvar confiere cierta dimensión satírica. La extravagante concejala en asuntos sociales pertenece al PAP, partido cuyos acrónimo e ideología motivan en la mente del espectador un paralelismo con el Partido Popular español: el PAP aparece como una proyección diegética y paródica del PP. La sátira estriba en el desfase entre los valores conservadores de este partido de derechas y el erotismo liberal y liberado reivindicado por Chon, por añadidura consumidora de cocaína. Ninfomanía y antropofagia conforman una especie de sexualidad alternativa poco compatible con el único modelo avalado por los sectores conservadores de la sociedad, a saber la heterosexualidad practicada en el marco del matrimonio y con fines esencialmente procreativos. La concejala asume totalmente su drogadicción y su marginalidad erótica -dos formas de excentrismo grotesco-, inspirándole ésta el título de un ensayo dedicado al sexo social, asunto "muy interesante e inexplorado hasta ahora": Una cerda en el PAP. Son precisamente opciones inéditas que pretende brindarles a sus conciudadanos, en una perspectiva progresista y hedonista: "A los ciudadanos hay que ofrecerles alternativas, que les hagan evolucionar y ser más felices”. Incluso parece considerar su apetito sexual desmesurado como una actitud vanguardista, que ya la caracterizaba a los cuatro años: "También en esto fui una adelantada de mi tiempo". Sin rechazar radicalmente la ideología de su partido, denuncia su apariencia conservadora, hasta anticuada ("la imagen de un partido desfasado y anclado en el pasado"), principal problema del PAP en su opinión. No reniega de la filiación 107 
ideológica entre la derecha española contemporánea y el conservadurismo franquista ("Yo creo que Franco fue un buen gobernante") pero sí expresa sus discrepancias con la concepción erótica del dictador ("en lo referente al sexo no se enteraba”), causa de sus frustraciones sensoriales y sensuales pasadas ("Me educaron bajo el grito de 'eso no se toca', 'eso no se come'. Dios mío, iqué tiempos!”). Su alegato a favor de una forma de socialismo sexual, fundado en la multiplicación de las relaciones íntimas como expresión de la solidaridad entre los hombres, hace de ella la portavoz de un partido de derechas que busca atraer a los "socialistas aburridos". El divorcio entre conservadurismo político y desmesura sexual se acompaña de un efecto humorístico de ruptura entre los dos lenguajes usados por la concejala. Por una parte, Chon pone la terminología política al servicio de sus demostraciones y su proselitismo a favor del PAP: se considera el sexo como un "asunto social" y cualquier individuo debe poder acceder al placer físico "sin prejuicios ni cortapisas", en nombre de un principio "democrático"; en el caso contrario, puede ser víctima de una situación de "marginación", dolorosa experiencia que la propia concejala vivió de niña. El recurso a esta jerga política revela una voluntad por parte del director de hacer escarnio de una retórica artificial y estancada y de un discurso político desacreditado por el contenido que se le asocia. Por otra parte, Chon recurre a un léxico grosero y atrevido para designar el acto sexual, sus propios genitales o los de sus amantes (“culos”, “paquetes”, “coño”, “pollones”, “que me follen”, “polla”): el registro usado revela la ausencia total de tabúes en el personaje y traduce verbalmente su impudor, sus costumbres liberales, incluso cierto mal gusto, reminiscencia de las primeras realizaciones de Almodóvar. Esta obscenidad por toques en el espacio del monólogo hace hincapié en una aprensión fragmentaria y metonímica de la anatomía humana, como se ha señalado antes en el caso del cuerpo-objeto masculino, y materializa el encuadre mental en los órganos fuentes de excitación y placer eróticos para Chon. Esta visión atomizada del organismo se revela típicamente grotesca: el discurso de la concejala (que brota de la boca), se enfoca en los orificios (el ano, la vagina) y protuberancias (el miembro viril), ofreciendo una puesta en escena del cuerpo grotesco fundada en la celebración de "lo bajo material y corporal" 108 
("le bas matériel et corporel") bajtiniano. En efecto, aperturas y excrecencias patentizan la materialidad del cuerpo y lo inscriben en un movimiento de rebajamiento ("rabaissement") espacial: de arriba hacia abajo, de la faz a los genitales, al vientre y al trasero (Bakhtine, 1965: 29-30). La ingestión del flan supone una trayectoria del alimento que va de la boca al ano pasando por el vientre mientras que las prácticas sexuales de Chon implican una comunicación de sus propios orificios con el pene y los pies de su pareja, siendo el pie el órgano-nexo entre el hombre y el suelo: los cuerpos se interpenetran, aboliendo las fronteras que los demarcan los unos de los otros. Satisfacción de las necesidades naturales y vida sexual se hallan en el centro de la concepción grotesca del organismo humano: anclan a éste en la tierra, en la materialidad. Chon absorbe el mundo, devora a sus amantes por la boca, por el sexo, por el ano y encarna por lo tanto este principio del rebajamiento grotesco y de la celebración corporal de la existencia. Aparece en este sentido como un personaje profundamente material y telúrico.

Por si fuera poco, la concejala no duda en entremezclar desde un punto de vista formal la descripción de sus fantasías y la demostración política: el ejemplo más emblemático es sin duda la exposición en tres puntos de los distintos modos en que usa el pie masculino cuando le practica una felación a su amante. Remata su descripción con una leve inflexión de voz y una mirada a la cámara que materializan un contacto directo con los espectadores extradiegéticos

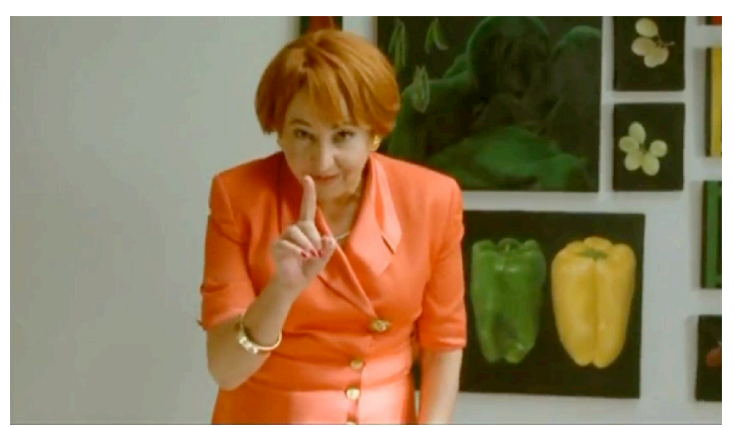
[foto 12], invitados a participar en la ficción como futuros miembros potenciales del PAP: "propongo a los ciudadanos para que lo experimenten en sus casas porque no hay nada más democrático que el placer”. Su confesión semeja un discurso con acentos demagógicos pronunciado en el marco de un mitin o un programa político. Además, la mirada a la cámara le confiere una dimensión metafílmica al fragmento puesto que el propio 
personaje parece derribar las barreras que separan la diégesis de nuestra realidad, sugiriendo que su prestación no es sino una representación.

Así pues, el humor satírico que caracteriza este monólogo nace de los efectos de ruptura y desfase entre preocupaciones políticas y consideraciones eróticas, entre conservadurismo derechista y prácticas sexuales liberales, entre retórica estancada y lenguaje crudo que celebra el cuerpo grotesco. A través de Chon, figura del exceso, es el mismísimo Almodóvar quien parece expresarse, haciendo escarnio de una derecha española por esencia poco propensa a alentar prácticas inéditas y nuevos esquemas sociales. “Antifranquiste sans le montrer” (“Antifranquista sin mostrarlo”) (Méjean, 2004: 13), si rechaza toda forma real de compromiso político - aunque sus tomas de posición se hacen cada vez más obvias -, se empeña con todo en construir una visión progresista de la sociedad: en el conjunto de su filmografía, desarrolla espacios de la diferencia y de la heterogeneidad, propicios entre otras cosas a la emergencia de sexualidades alternativas (homosexualidad, travestismo, transexualidad, sadomasoquismo...) y al desplazamiento de las nociones tradicionales de centro y margen, fundamentales en la problemática grotesca.

A la luz de los trabajos bajtinianos sobre lo grotesco, se ha procurado esbozar una posible lectura de La concejala antropófaga. Pedro Almodóvar inserta este cortometraje en su filmografía y teje una red de relaciones transtextuales que convida al espectador a un desciframiento de las referencias sembradas no sólo en este relato fílmico sino también en la otra secuencia de la obra ficticia Chicas y maletas. El director forja un personaje con prácticas políticas y sexuales poco ortodoxas, celebrando la materialidad del cuerpo grotesco: éste es inagotable, antropófago, en interacción constante con un mundo que engulle, absorbe y del que se apropia. La figura de esta concejala ex-céntrica en todos los sentidos del término se convierte en la abanderada de un partido que parodia claramente la actual derecha española. Empero, el designio del cineasta parece menos político que lúdico. Además de divertir a su público con una marioneta que se agita en el escenario de su teatro, el cineasta-demiurgo sugiere que se debe leer la antropofagia abiertamente 
reivindicada por Chon como una metáfora de su propio proceso creativo: Almodóvar interacciona con su obra y su mundo personal, los despedaza, los engulle, los digiere y los recicla, erigiendo la autofagia en postura estética. ¿Acaso será necesario devorarse a sí mismo para seguir creando?

\section{Referencias bibliográficas}

BAKHTINE, Mikhaïl (1965). L'œuvre de François Rabelais et la culture populaire au Moyen-Âge et sous la Renaissance, Paris: Gallimard, 1982, traduction française d'Andrée Robel, 471 p.

FAUCONNIER, David, EIZYKMAN, Claudine (dir.) (2003). L'esprit grotesque dans le cinéma espagnol : 196o-1965 (tome I), thèse de doctorat, Université Paris 8, 349 p.

FREUD, Sigmund (1905). Trois essais sur la théorie de la sexualité, Paris : Gallimard, coll. «Idées», 1962, traduction française de B. ReyerchonJouve, $189 \mathrm{p}$.

GENETTE, Gérard (1982). Palimpsestes. La littérature au second degré, Paris : Seuil, $573 \mathrm{p}$.

LENQUETTE, Anne (2000). “Almodóvar y la Movida: Patty Diphusa, una obra de juventud desconocida”, España contemporánea, Ohio State University / Universidad de Zaragoza, otoño, ${ }^{\circ} 2$, pp. 75-92.

MÉJEAN, Jean-Max (2004). Pedro Almodóvar, Rome: Gremese, coll. «Les Grands réalisateurs», $121 \mathrm{p}$.

VIDAL, Nuria (2000). El cine de Almodóvar, Barcelona: Destino, 440 p. 